\title{
Application of optimal artificial intelligence based tuned controllers to a class of embedded nonlinear power system
}

\author{
Magdy A. S. Aboelela \\ Faculty of Engineering, Cairo University, Egypt \\ Email: aboelelamagdy@ staff.cu.edu.eg
}

\begin{tabular}{l}
\hline \hline Article Info \\
\hline Article history: \\
Received May 19, 2019 \\
Revised Oct 20, 2019 \\
Accepted Nov 15, 2019 \\
\hline
\end{tabular}

Keywords:

Brain emotional learning based intelligent controllers Fraction order proportionalintegral-derivative controllers Matlab/simulink

Nonlinear systems

Proportional-integral-derivative controllers

\begin{abstract}
This paper studies the implementation of the Bat Inspired Algorithm (BIA) as an optimization technique to find the optimal parameters of two classes of controllers. The first is the classical Proportional-Integral-Derivative (PID). The second is the hybrid fractional order and Brain Emotional Intelligent controller. The two controllers have been implemented, separately, for the load frequency control of a single area electric power system with three physical imbedded nonlinearities. The first nonlinearity represents the generation's rate constraint (GRC). The second is owing to the governor dead band (GDB). The last is due to the time delay imposed by the governorturbine link, the thermodynamic process, and the communication channels. These nonlinearities have been embedded in the simulation model of the system under study. Matlab/Simulink software has been applied to obtain the results of applying the two classes of controllers which have been, optimally, tuned using the BIA. The Integral of Square Error (ISE) criterion has been selected as an element of the objective function along with the percentage overshoot and settling time for the optimum tuning technique of the two controllers. The simulation results show that when using the hybrid fractional order and Brain Emotional Intelligent controller, it gives better response and performance indices than the conventional ProportionalIntegral-Derivative (PID) controllers.
\end{abstract}

This is an open access article under the $\underline{C C B Y-S A}$ license.

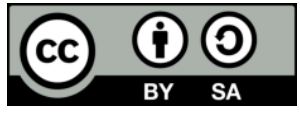

\section{Corresponding Author:}

Magdy A. S. Aboelela,

Faculty of Engineering,

Cairo University,

Giza Governorate 12613, Egypt.

Email: aboelelamagdy@staff.cu.edu.eg

\section{INTRODUCTION}

Due to unremitting development of size and complexity of electrical power system, the problem of maintaining the power and frequency free from oscillations has become rapidly crucial because of irregular load variations and imbedded system nonlinearities [1]. These unexpected load variations result in the mismatch of generated power and load demand for consumption. This will finally distresses the quality and reliability of electric power supply. This can be achieved by the load frequency control (LFC) ideologies. Nowadays, a lot of work is going on to make the systems intelligent so the systems can successfully serve the benefits of mankind [2-3].

The main goal of operation of the LFC in the single area or multi area power systems is to maintain the frequency within the permissible limits. In the past few years, enormous improvement has been made in the area of load frequency control of a single area power system and multi area as well [4-5]. Designing 
the LFC with the help of PID controllers makes it prominent and trustworthy, but the main challenge is to decide the parameters of controllers [6-7].

To have better behavior from any controller, its parameters should be optimally tuned. The conventional methods face some difficulties to achieve this purpose, such as complex mathematical equations for large systems. Several approaches such as optimal, Genetic Algorithm (GA), Particle Swarm Optimization (PSO), Bacterial Foraging Optimization (BFO), etc., for the design and optimization of the LFC system, have been reported in the literature [8]. Modern optimal control concept for AGC designs of interconnected power system was firstly presented by [9]. Genetic algorithms (GAs) have been extensively considered for the design of Automatic Generation Control (AGC). Optimal PID and fractional-order PID control parameters have been applied by the GAs technique for interconnected, equal non-reheat and reheat type two generating areas [10]. In [11], the parameters of PID sliding-mode used in LFC of multi-area power systems with nonlinear elements are optimized by GA. In [12], GA is used to compute the decentralized control parameters to reach to an optimum operating point for a realistic system comprising generation rate constraint (GRC), dead band, and time delays. AGC using integral controller and PI controller based on PSO is reported in [13]. In [14], the parameters of PI controller are evaluated using PSO [13]. In [15], a robust PID controller based on ICA is used for LFC application. The authors of [16-18] have proposed bacterial foraging optimization algorithm (BFOA) for designing PI and PID-based load frequency controllers.

For a single area power system, the problem of LFC and AGC has been treated by several researchers. This includes a variety of techniques such as gravitational search algorithm [19], the modified particle swarm optimization [20], the application of artificial neural network [20], optimal control design [21], fuzzy logic [22-23], proportional-integral-observer techniques [24], and LQR and Legendre wavelet function [25]. Finally, the automatic generation control of single area power system with multisource power generation has been studied in [26]. All these researches deal only with the case where no nonlinearities exist in the control loops.

To include the nonlinearities previously mentioned in this article, we have selected a special category of controllers which are the Fractional Order PID controllers (FOPID) [27-33] and Brain Emotional Learning based intelligent controllers (BELBIC) [34-35].

\section{CLASSICAL PID CONTROLLER}

The PID controller is considered to be an important component in industrial control systems. This is because of its capability of reducing the steady state error and enhancing the dynamic response and other static characteristics. The PID controller is expressed, mathematically, by the next equation [36]:

$$
u(t)=K_{\mathrm{p}} \mathrm{e}(\mathrm{t})+K_{\mathrm{i}} \int_{0}^{\mathrm{t}} \mathrm{e}(\tau) \mathrm{d} \tau+K_{\mathrm{d}} \frac{\mathrm{de}(\mathrm{t})}{\mathrm{dt}}
$$

Where $\mathrm{e}(\mathrm{t})$ is the system error, $K_{\mathrm{p}}$ is the proportional gain, $K_{\mathrm{i}}$ is the integral gain, $K_{\mathrm{d}}$ is the derivative gain and $u(t)$ is the output of the controller.

\section{FRACTIONAL ORDER CONTROLLER}

The fractional calculus is implemented to obtain the solution for many scientific and engineering applications. In last ten years it is being acknowledged by its ability to yield a better modeling and control in many dynamical systems [28]. The fractional order controller explores good robustness and gives better behavior due to tuning five or four parameters $\left(K_{p}, K_{i} . K_{d} . \lambda . \delta\right)$ instead of three or two parameters $\left(K_{p}, K_{i} . K_{d}\right)$ in classical PID controllers [29]. The fractional controller form is expressed, mathematically, as follows [30]:

$$
U(s)=K_{p} * E(s)+K_{i} * E(s) * s^{-\lambda} K_{d} * E(s) * s^{\delta}
$$

Where $\mathrm{E}(\mathrm{s})$ denotes the error signal, $U(s)$ is control signal, $K_{P}, K_{i}$ and $K_{d}$ are proportional, integral and derivative coefficients respectively, $\lambda$ and $\delta$ are power of 's' in integral action and derivative action respectively.

One of the methods to realize the fractional order controllers is known as the Oustaloup method [31]. This method relies on the approximation of a function as given by (3) and (4).

Some continuous filters have been summarized in [31]. Among the filters, the well-established Oustaloup recursive filter has an acceptable fitting to the fractional-order differentiators. Assume that the expected fitting range is $\left(\omega_{b}, \omega_{h}\right)$. The filter can be expressed as 


$$
\widehat{H}(s)=K \prod_{k=-N}^{N} \frac{s+\omega_{k}^{\prime}}{s+\omega_{k}}
$$

Where the poles, zeros, and gain of the filter of order $N$ can be evaluated as

$$
\begin{aligned}
& \omega_{k}^{\prime}=\omega_{b}\left(\frac{\omega_{h}}{\omega_{b}}\right)^{\frac{k+N+\frac{1}{2}(1-\gamma)}{2 N+1}} \\
& \omega_{k}=\omega_{b}\left(\frac{\omega_{h}}{\omega_{b}}\right)^{\frac{k+N+\frac{1}{2}(1+\gamma)}{2 N+1}}
\end{aligned}
$$

and

$$
K=\omega_{h}^{\gamma}
$$

Thus, any signal $y(t)$ can be filtered by this filter and the output of the filter can be treated as an approximation for the derivative part of the FOPID with $\gamma=\delta$ or the integral counterpart with $\gamma=-\lambda$ [32-34]. The resulted transfer function of the FOPID is the sum of the proportional term $K_{p}$ plus the filter approximation of the integral term $\left(K_{i} s^{-\lambda}\right)$ plus the derivative term $\left(K_{d} s^{\delta}\right)$.

\section{BAT INSPIRED ALGORITHM (BIA)}

The bat inspired algorithm (BIA) is a new artificial intelligence (AI) technique. It is based on the echolocation behavior of bats in searching their victims [35-36]. These bats locate its prey by emitting a series of ultrasound pulses and listen for the echoes. The reflected ultrasound waves have different levels of sound and time delays. This will enable each bat to get a specific prey. The BIA is summarized in the following steps,

Step 1 : All bats use echolocation to evaluate the distance and identify between prey and barrier.

Step 2 : Each bat flies with a velocity $\left(v_{i}\right)$ at position $\left(x_{i}\right)$, having fixed frequency $\left(f_{\min }\right)$ varying wavelength $(\lambda)$, and loudness $\left(L_{o}\right)$ to seek a prey. The bat tunes the frequency of its emitted pulse in the range $\left(f_{\min }, f_{\max }\right)$ and adjusts the rate of pulse emission $(r)$ in the range of $[0,1]$ according to target closeness.

Step 3 : Frequency, loudness, and pulse emission rate of each bat is varied.

Step 4 : Their loudness changes from a large value $L_{o}$ to a minimum constant value $L_{\text {min }}$.

The position $x_{i}$ and velocity $v_{i}$ of each bat are updated during the optimization process. The positions $x_{i}^{t}$ and velocities $v_{i}^{t}$ at a time step $t$, are computed as follows:

$$
\begin{aligned}
& f_{i}=f_{\min }+\left(f_{\max }-f_{\min }\right) \alpha, \quad \alpha \in\left[\begin{array}{ll}
0 & 1
\end{array}\right] \\
& v_{i}^{t}=v_{i}^{t-1}+\left(x_{i}^{t}-x^{*}\right) f_{i} \\
& x_{i}^{t}=x_{i}^{t-1}+v_{i}^{t}
\end{aligned}
$$

Where $\alpha$ is a random value derived from a uniform distribution function. The current global best location $x^{*}$ is obtained after comparing all locations among all bats. Since the velocity is given $v_{i}=\lambda_{i} f_{i}$, a variance in either $f_{i}$ or $\lambda_{i}$ results in a velocity change. The algorithm is started by defining a random frequency $f_{i} \in\left[f_{\min } f_{\max }\right]$ for every bat. The best solution is selected between current solutions in the local search. Thus by using random walk, a new solution for each bat is developed locally.

$$
x_{\text {new }}=x_{\text {old }}+\varepsilon L^{t}, \quad \varepsilon \in[-1,1]
$$

Where $\varepsilon$ is a random number and $L^{t}$ is the mean loudness of all bats at this time step. Loudness decreases and the rate pulse emission increases after a bat get its prey then any convenience value can be selected for loudness. When the bat has just found a prey, this means that loudness is zero and the bat temporarily stops emitting any sound. This is governed by the following equations: 


$$
\begin{aligned}
& L_{i}^{t+1}=\beta L_{i}^{t}, \quad 0<\beta<1 \\
& r_{i}^{t+1}=r_{i}^{0}\left(1-e^{-\gamma t}\right), \quad \gamma>0
\end{aligned}
$$

As the time approaches infinity, zero loudness is achieved and $\gamma_{i}^{t}=\gamma_{i}^{0}$. The steps of BIA are summarized in the following code [36].

\section{BRAIN EMOTIONAL LEARNING BASED INTELLIGENT CONTROLLERS (BELBIC)}

BELBIC is an intelligent controller which is proposed by Caro Lucas [36]. It shown in Figure 1. It adopts the network model developed by Moren and Balkenius to mimic those parts of the brain which are known to produce emotion (namely, the amygdala, orbitofrontal cortex, thalamus and sensory input cortex).

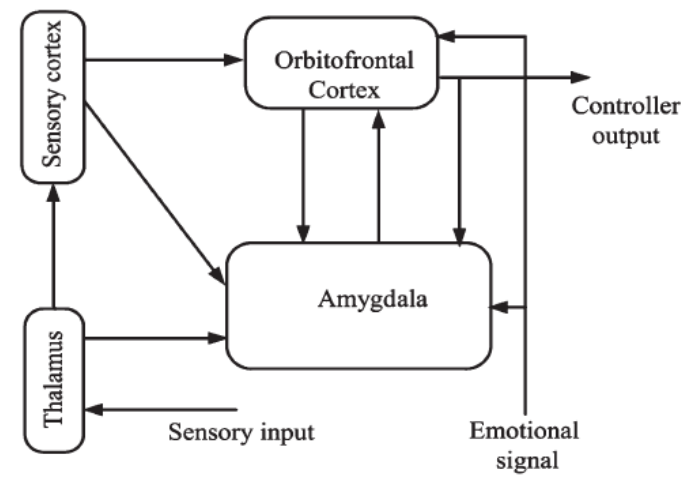

Figure 1. The computational model of BELBIC

The main parts that are responsible for performing the learning algorithms are orbitofrontal cortex and amygdala. These are shown in Figures 2 and 3. The BELBIC has some sensory inputs. One of the designer's tasks is to specify the sensory inputs. The BELBIC has two states for each sensory input. One of these two is amygdala's output and another is the output of orbitofrontal cortex.

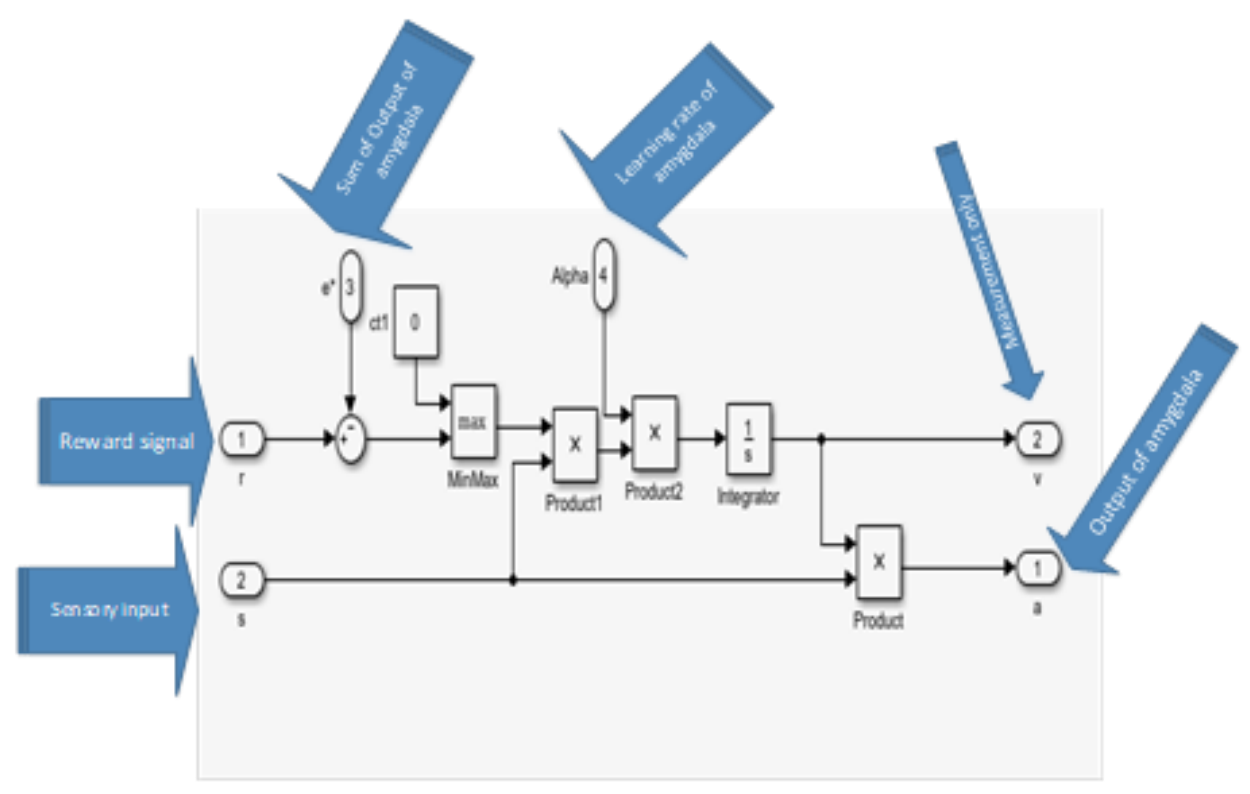

Figure 2. Amygdala internal components 


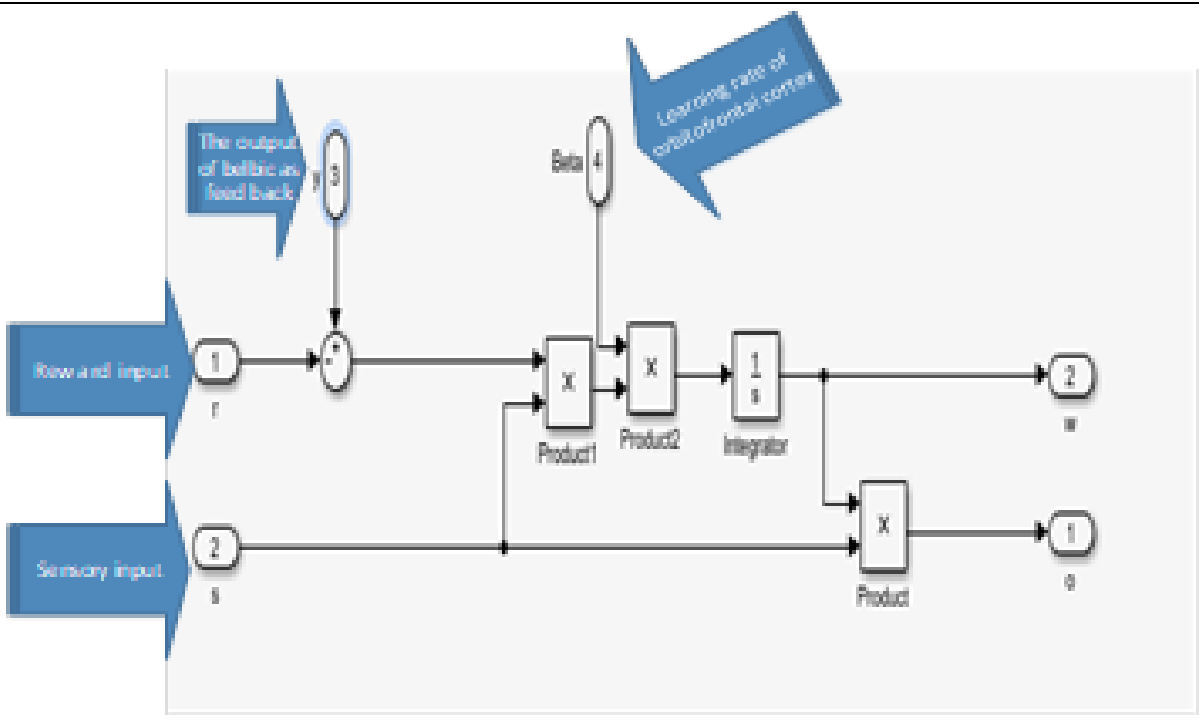

Figure 3. Orbitofrontal cortex internal components

From mathematical view point, this converts into supplementing the final result either through additions or subtraction respectively. It is apparent that orbitofrontal part takes care of the latter and amygdala produces the signal which aids to find the final result. Likewise, a plastic connection identifies connections without any adjustable weights and a connection which can learn indicates.

The Amygdala output is A and it can be represented as

$$
\begin{aligned}
& A_{i}=S_{i} * V_{i} \\
& \nabla V_{i}=\alpha * S_{i} * \max \left(0, \text { rew }-\sum A_{i}\right)
\end{aligned}
$$

Where: $V_{i}$ is the weight factor of amygdala for input number I and $S_{i}$ is the sensory input number i. $\alpha$ denotes the learning rate parameter which is used to adjust the learning speed. Its value is set between 0 (no learning) and 1 (instant adaptation).

The Orbitofrontal cortex output is $\mathrm{O}$ and can be given as

$$
\begin{aligned}
& O_{i}=S_{i} * W_{i} \\
& \Delta W_{i}=\beta * S_{i}\left(r e w-\sum \boldsymbol{A}_{\boldsymbol{i}-} \sum \boldsymbol{O}_{\boldsymbol{i}}-\operatorname{Max}\left(S_{i}\right)\right)
\end{aligned}
$$

Where: $W$ is the weight of the orbitofrontal cortex for the related sensory input and $\beta$ denotes the Orbitofrontal learning rate. The output of BILBIC is given as $U$ and can be denoted as

$$
\mathrm{U}=\text { Amygdala output }- \text { Orbitofrontal cortex }=\sum A_{i-} \sum O_{i}
$$

\section{APPLICATION}

The methodologies described herein can be applied on a single area power system where the objective is to maintain the working frequency change at a permissible range when the loads are changed suddenly over or under the planned values. The system consists of three main components. These are the governer, the turbine and the generator and load. The block diagrams implementing the PID and Hybrid FOPID-BELBIC controllers are delineated in Figures 4 and 5. The parameters for these diagrams are listed in Table 1. The systems are subjected to a sudden load change of $0.05 \mathrm{p}$.u. The characteristics of the turbine saturation (GRC), the GDB and the time delay as non-linear elements are displayed in Table 2. Noticeably, the proposed Simulink-based model can clearly accommodate the governor dead bands (GDBs), the generation rate constraints (GRC) and the transport delays are shown in Figures 4 and 5. Dead bands are imposed in the model using backlash nonlinearities where $0.05 \%$ is considered. The GRC of the thermal area is set to $0.01 \mathrm{p} . \mathrm{u} . \mathrm{MW} / \mathrm{s}$. 

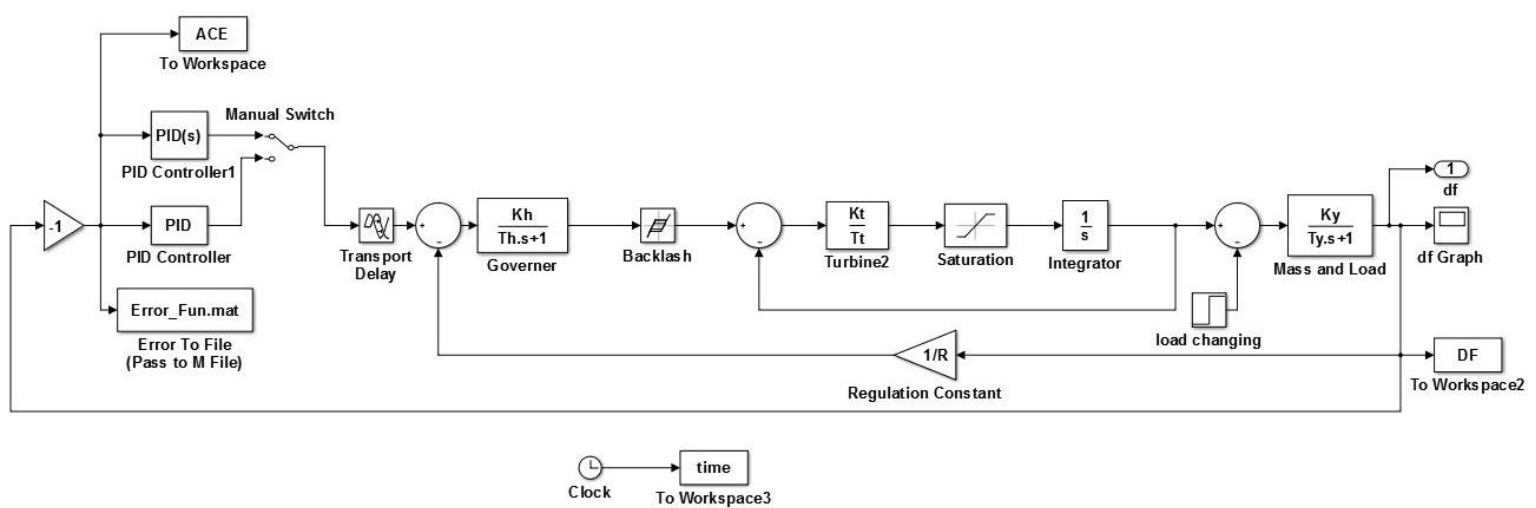

Figure 4. The simulation diagram of the LFC with classical PID controllers including the embedded system nonlinearities

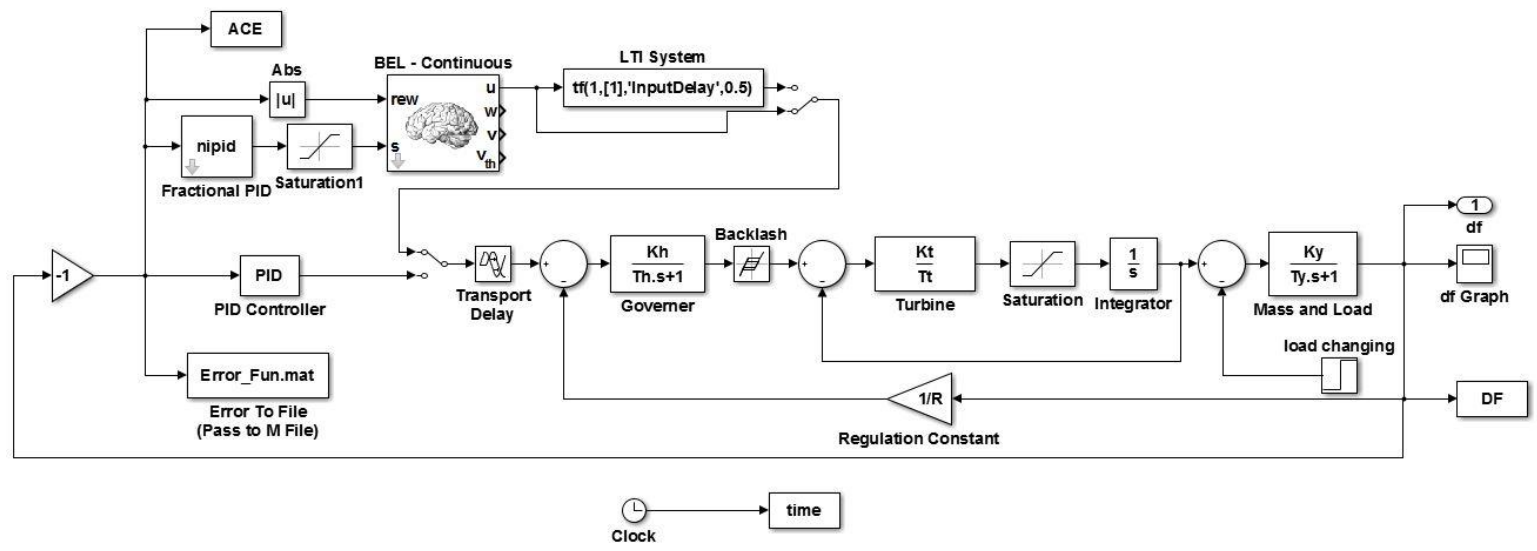

Figure 5. The simulation diagram of the LFC with hybrid FOPID and BELBIC controllers including the embedded system nonlinearities

Table 1. The simulation model parameters

\begin{tabular}{ccc}
\hline Parameter & Units & Value \\
\hline Steam governor time constant $\left(T_{h}\right)$ & seconds & 0.08 \\
Steam governor gain factor $\left(K_{h}\right)$ & - & 1 \\
Turbine time constant $\left(T_{t}\right)$ & seconds & 0.3 \\
Turbine gain factor $\left(K_{t}\right)$ & - & 1 \\
Mass and generator time constant $\left(T_{y}\right)$ & seconds & 20 \\
Mass and generator gain factor $\left(K_{y}\right)$ & - & 120 \\
Governor speed regulation parameter & (Hz/p.u.MW) & 2.4 \\
\hline
\end{tabular}

Table 2. The characteristics of the turbine saturation (GRC), the GDB and the time delay

\begin{tabular}{ccc}
\hline Non-linear Element & Symbole & Data \\
Turbine GRC & Saturated at \pm 0.01 [p.u MW/second] \\
GDB & & $1-2$ seconds \\
\hline
\end{tabular}


The parameters of the Bat Inspired Algorithm are given in Table 3 [39].

Table 3. The parameters of the bat inspired algorithm

\begin{tabular}{ccc}
\hline Parameter & Description & Value \\
\hline $\mathrm{n}$ & Population size & $10-40$ \\
$\mathrm{~N}$ & Number of generations & 100 \\
$\mathrm{~A}$ & Loudness & 0.5 \\
$\mathrm{r}$ & Pulse rate & 0.5 \\
$\mathrm{Q}_{\min }$ & Minumum frequency & 0 \\
$\mathrm{Q}_{\max }$ & Maximum frequency & 2 \\
$\alpha$ & constant & 0.95 \\
$\gamma$ & constant & 0.9 \\
\hline
\end{tabular}

The optimization fitness function $f_{i}$ at iteration $i$ is given as

$$
f_{i}=\frac{1}{I S E_{i}}
$$

So that

$$
I S E_{i}=\int_{0}^{\infty} e_{i}^{2}(t) d t+\mathrm{P} . \mathrm{O}+\text { Settling Time }
$$

Where $I S E_{i}$ is the integral-square-error index at iteration $i, e_{i}$ is the area control error index (ACE) at iteration $i$, P.O is the percentage overshoot of the frequency-time response curve. The definitions of P.O and settling time are depicted in [7].

\section{RESULTS AND DISCUSSION}

The frequency control single area power system with GRC, GDB, and time delay nonlinearities incorporating the PID and Hybrid FOPID-BELBIC controllers has been investigated in this research. The Bat Inspired Algorithm has been utilized to tune the proposed controllers. The tuning process of the two controllers has been achieved using the Matlab/Simulink software. The outcomes of the tuning procedure using the Integral Square Error criterion are summarized in Table 4.

Table 4. Results of the two proposed controllers

\begin{tabular}{cccccccc}
\hline Controller & \multicolumn{7}{c}{ Parameters } \\
\hline PID & $K_{p}$ & $K_{d}$ & $K_{i}$ & - & - & - & - \\
& 0.54 & 1.83 & 0 & - & - & - & - \\
ISE & & \multicolumn{7}{c}{$K_{d}$} & \multicolumn{1}{c}{$K_{d}$} & $K_{d}$ & $r_{i}$ & $\alpha$ & $\beta$ \\
& $K_{p}$ & $K_{d}$ & $K_{i}$ & 0.25 & 0.32 & $4.73 \mathrm{e}-05$ & $4.50 \mathrm{e}-05$ \\
FOPID-BELBIC & 0.54 & 1.83 & 0.86 & 0.25 \\
ISE & & & \multicolumn{7}{c}{12.1929} \\
\hline
\end{tabular}

As stated in the literature, a proportional controller $\left(K_{p}\right)$ will have the effect of reducing the rise time and will reduce, but never eliminate, the steady-state error. An integral control $\left(K_{i}\right)$ will have the effect of eliminating the steady-state error, but it may make the transient response worse. A derivative control $\left(K_{d}\right)$ will have the effect of increasing the stability of the system, reducing the overshoot, and improving the transient response [7]. This is clear when we look at the frequency response of the system without controller (by setting the values of $K_{p}$ to $1, K_{d}$ to o and $K_{i}$ to 0 in Figure 3. This response, as shown in Figure 6 , is oscillatory with a little damping effect. This will explain why we should seek for a special controller which will damp this oscillation and achieve a system with steady-state error.

As stated earlier, the first alternative is to implement the PID controller. The difference between PID and PID(s) in Figure 3 is that the parameters of the first controller $\left(K_{p}, K_{d}\right.$, and $\left.K_{i}\right)$ are tuned using the BIA but those of the second controller, PID(s), are obtained a special optimization technique associated with this block in Matlab.

The frequency response of the PID controller as shown in Figure 7 is somewhat acceptable but there are two main features. The first is the ripple effect when trying to reach the steady state. Second is the high value of ISE index. The tuned parameters of this controller are shown in Table 4 . The tuning procedure using the BIA yields zero value for the integral gain $K_{i}$. This is expected since we are trying to reduce

\footnotetext{
Application of optimal artificial intelligence based tuned controllers to a class of ... (Magdy A. S. Aboelela)
} 
the overshoot in the objective function. Trials have been made to limit the $K_{i}$ to values greater than zero in the tuning procedure but this leads to an unstable system.

On the contrary, the hybrid FOPID-BELBIC controller is shown in Figure 8. The tuning step has been achieved using the BIA. The results of the tuning procedure yield 5 parameters; $K_{p}, K_{d}, K_{i}, r_{i}$ and $r_{d}$; for the FOPID controller and 2 parameters; $\alpha$ and $\beta$; for the BELBIC. The estimated values for these 7 parameters are delineated in Table 4 . This has been achieved using the BIA parameter setting delineated in Table 3. It is clear that this hybrid FOPID-BELBIC will yield a smaller value for the ISE index compared with the conventional PID controller. This, of course, cab be arrived to with little high computation time.

The frequency response obtained by applying the classical PID controller and the hybrid FOPIDBELBIC is displayed in Figures 6 and 7. The two curves illustrate the fact that we can not arrived, exactly, to a zero state error. This is due to the GRC, GBD, and time delay nonlinearities. One more thing, the increase of the time delay will result in unstable system. The analysis of these effects will be studied in another endeavor.

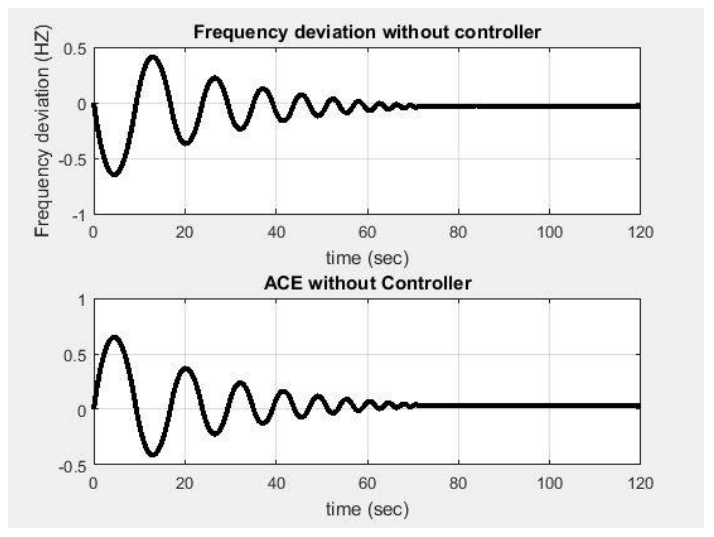

Figure 6. The simulation results without controller with time delay of 1.5 seconds

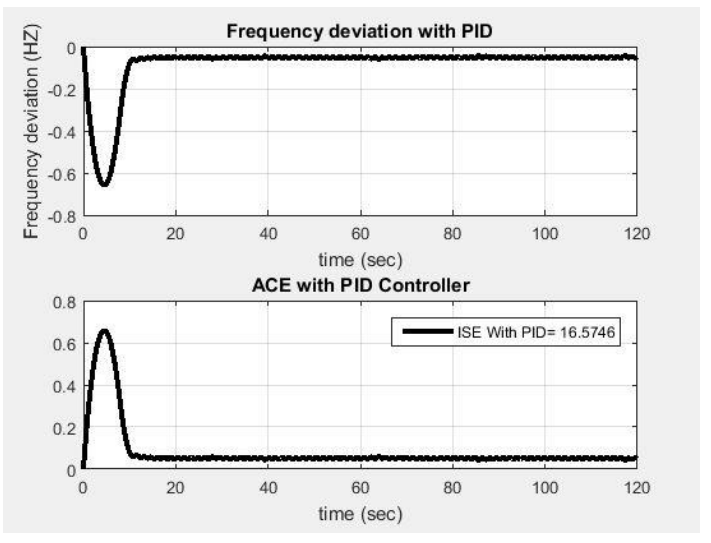

Figure 7. The simulation results with PID controller with time delay of 1.5 seconds

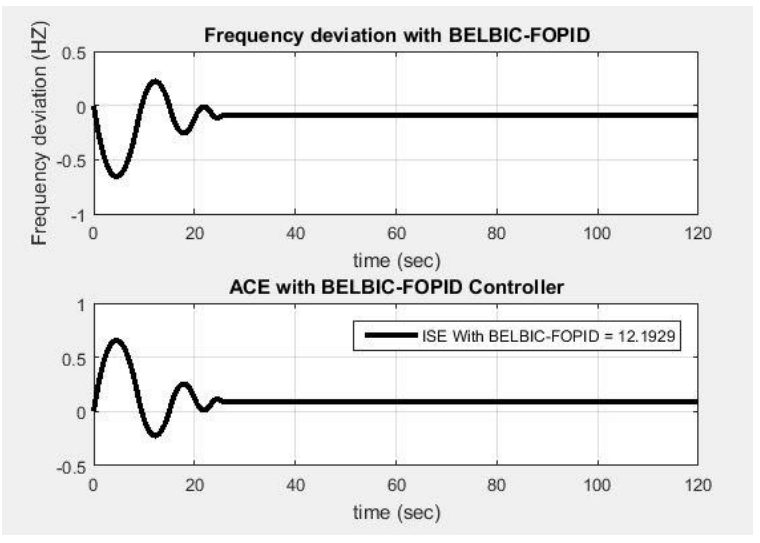

Figure 8. The simulation results with hybrid FOPIDBELBIC controller with time delay of 1.5 seconds

\section{CONCLUSION}

In this paper, the application of two classes of controllers to a single area load frequency control has been investigated. The presented system has three sources of nonlinearities. These are the GRC, GBD, and time delay. The first controller is the classical PID controller while the second is the hybrid FOPID-BELBIC. The parameters of these two controllers have been optimally tuned using the BIA. Results show that the second controller will behave better than the first one. This is because of the nonlinearity nature of the second controller. Furthermore, the effect of dealing with the three embedded nonlinearities, the GRC, GBD, and time delay, have been studied but more detailed research is recommended. 


\section{REFERENCES}

[1] L. Dong, "Decentralized load frequency control for an interconnected power system with nonlinearities," In Proceedings of the American Control Conference (ACC), 2016.

[2] M. Elsisi, M. Soliman, M. A. S. Aboelela, W. Mansour, "GSA-based design of dual proportional integral load frequency controllers for nonlinear hydrothermal power system," World Academy of Science, Engineering, and Technology, vol. 9, pp. 1242-1248, 2015.

[3] V. Singh, A. Kumar Singh, V. Chauhan, and A. Kumar Bharadwaj, "Load frequency control of single area power system using JAYA algorithm," International Research Journal of Engineering and Technology (IRJET), vol. 4, no. 7, 2017.

[4] H. Bevrani, Robust power system frequency control, Springer, 2009.

[5] D. Kothari and I. Nagrath, Power system engineering, New York: McGraw-Hill, 2008.

[6] D. Xue, Y. Chen, and D. P. Atherton, Linear feedback control: Analysis and design with MATLAB, Philadelphia, PA: Society for Industrial \& Applied Mathematics, 2008.

[7] K. J. Åström, K. J. Aström, T. Hägglund, K. J. Astrom, T. Hagglund, and T. H. Hagglund, PID controllers: Theory, design and tuning, International Society for Measurement and Control, 1995.

[8] S. K. Pandey, S. R. Mohanty, and N. Kishor, "A literature survey on load-frequency control for conventional and distribution generation power systems," Renewable and Sustainable Energy Reviews, vol. 25, pp. 318-334, 2013.

[9] S. P. Ghoshal, "Application of GA/GA-SA based fuzzy automatic generation control of a multi-area thermal generating system," Elect. Power Syst. Res., vol. 70, pp. 115-127, 2004.

[10] C. Ismayil, R.S. Kumar, T.K. Sindhu, "Optimal fractional order PID controller for automatic generation control of two-area power systems," International Transactions on Electrical Energy Systems, 2014.

[11] L. Pinkag, Z. Hengjun, and L. Yuyun, "Genetic algorithm optimization for AGC of multi-area power systems," In Proc. of IEEE Region 10 conference on computers, communications, control and power engineering (TENCON'02), pp. 1818-21, 2002.

[12] H. Golpira, H. Bevrani, "Application of GA optimization for automatic generation control design in an interconnected power system," Energy Conversion and Management, vol. 52, pp. 2247-2255, 2011.

[13] Y. L. Abdel-Magid, M. A. Abido, "AGC tuning of interconnected reheat thermal systems with particle swarm optimization," 10th IEEE international conference on electronics, circuits, and systems, vol. 1, pp. 376-9, 2003.

[14] H. Gozde, M. C. Taplamacioglu, I. Kocaarslan, and M. A. Senol, "Particle swarm optimization based PI-controller design to load frequency control of a two area reheat thermal power system," J. Therm Sci Tech., vol. 30, no. 1, pp. 13-21, 2010.

[15] H. Shabani, B. Vahidi, and M. Ebrahimpour, "A robust PID controller based on imperialist competitive algorithm for load-frequency control of power systems," ISA Trans., vol. 52, no. 1, pp. 88-95, 2013.

[16] B. Paramasivam and I.A.Chidambaram, "Bacterial foraging optimization based load frequency control of interconnected power systems with static synchronous series compensator," International Journal of Latest Trends in Computing, vol. 1, no. 2, 2010.

[17] J. Nanada, S. Mishra, and L. C. Saika, "Maiden application of bacterial foraging-based optimization technique in multi-area automatic generation control," IEEE Trans. Power Syst., vol. 24, no. 2, pp. 602- 609, 2009.

[18] P. Anitha, P. Subburaj and K. Vivek Kumar, "Bacterial foraging optimization based load frequency control of interconnected power systems," International Journal of Advanced Research in Biology Engineering Science and Technology (IJARBEST), vol. 2, no. 15, 2016.

[19] S. Duman; N. Yorukeren And I. Hakki Altas, "Load frequency control of a single area power system using gravitational search algorithm," Innovations in Intelligent Systems and Applications (INISTA), 2012.

[20] S. Kr. Gautam and N. Goyal, "Improved particle swarm optimization based load frequency control in a single area power system," Annual IEEE India Conference (INDICON), 2010.

[21] M. Lüy, İ. Kocaarslan, E. Çam, M. C. Taplamacioğlu, "Load frequency control in a single area power system by artificial neural network (ANN)," In Proceedings of the 4th International Conference on TPE, pp. 26-29, 2008.

[22] K.Swetha and D. Vijaya Kumar, "Load frequency control in a single area power system using optimal control design" International Journal of Scientific \& Engineering Research, vol. 6, no. 7, 2015.

[23] Y. R. Prajapati and S. Y. Prajapati, "A single area load frequency control (LFC): Comparative study based on integral and fuzzy logic controller," International Journal of Latest Technology in Engineering, Management \& Applied Science (IJLTEMAS), vol. 5, no. 1, 2016.

[24] M. A. Tammam, M. A. S. Aboelela, M. A. Moustafa and A. E. A. Seif, "Load frequency controller design for interconnected electric power system," In Proceedings of the 55th Annual Power Industry division Symposium POWID, 2012.

[25] Ahmed Hussein, S. Sadeem Salih and Y. Ghazi Ghasm, "Implementation of proportional-integral-observer techniques for load frequency control of power system," In the Proceedings of The 7th International Conference on Sustainable Energy Information Technology, 2017.

[26] H. Elaydi and M. Wadi, "Optimal controller for single area load frequency control via lqr and legendre wavelet function," Journal of Automation and Control, vol. 3, no. 2, pp. 43-47, 2015.

[27] K. S. S. Ramakrishna and T. S. Bhatti, "Automatic generation control of single area power system with multi-source power generation," Proceedings of the Institution of Mechanical Engineers Part A: Journal of Power and Energy vol. 222, no. 1, pp. 1-11, 2008.

[28] S. Das, Functional fractional calculus, Springer Science \& Business Media, 2011.

[29] K. B. Oldham and J. Spanier, The fractional calculus: Theory and applications of differentiation and integration to arbitrary order, United States: Dover Publications, 2006. 
[30] Zamani A, S. M. Barakati and S. Yousofi-Darmian, "Design of a fractional order PID controller using GBMO algorithm for load-frequency control with governor saturation consideration," ISA Trans., vol. 64, pp. 56-66, 2016.

[31] Pan and S. Das, "Fractional order load-frequency control of interconnected power systems using chaotic multiobjective optimization," Journal of Applied Soft Computing, vol. 29, pp. 328-344, 2015.

[32] S. A. Taher, M. H. Fini, and S F. Aliabadi, "Fractional-order PID controller design for LFC in electric power systems using imperialist competitive algorithm," Ain Shams Engineering Journal, vol. 5, no. 1, pp. 121-135, 2014.

[33] M. R. Dastranj, M. Rouhani, and A. Hajipoor, "Design of optimal fractional order PID controller using PSO algorithm," International Journal of Computer Theory and Engineering, pp. 429-432, 2012.

[34] J. Y. Cao, J. Liang, and B. G. Cao, "Optimization of fractional-order PID controllers based on genetic algorithms," 4th IEEE International Conference on Machine Learning and Cybernetics, vol. 9, pp. 5686-5689, 2005.

[35] S.M. Kamali Nalladurai And R.S.D. Wahida Banu, "LFC of two interconnected power system using intelligent controller method," U.P.B. Sci. Bull., Series C, vol. 77, no. 1, 2015.

[36] C. Lucas, D. Shahmirzadi, and N. Sheikholeslami, "Introducing BELBIC: Brain emotional learning based intelligent controller," International Journal of Intelligent Automation and Soft Computing, vol. 10, pp. 11-22, 2004.

[37] F. Xue, Y. Cai, Y. Cao, Z. Cui and F. Li, "Optimal parameter settings for bat algorithm," Int. J. Bio-Inspired Computation, vol. 7, no. 2, 2015.

\section{BIOGRAPHIES OF AUTHORS}

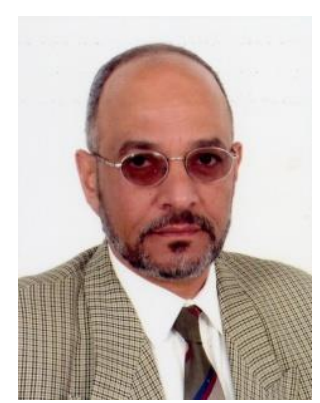

Magdy A.S. ABOELELA has been graduated from the electrical engineering department (Power and Machines section) in the faculty of engineering at Cairo University with Distinction and honor degree in 1977. He received his M.Sc. degree in automatic control from Cairo University in 1981. He received his Ph.D. in computer aided system engineering from the state university of Ghent, Belgium in 1989. He was involved in the MIT/CU technological planning program from 1978 to 1984 . He has been appointed as demonstrator, assistant professor, lecturer, associate professor and professor all at Cairo University where he is currently enrolled. He has given consultancy in information technology and computer science mainly for CAP Saudi Arabia, SDA Engineering Canada, Jeraisy Computer and Communication Services and other institutions. He has been appointed as a visiting professor at Case Western Reserve University (USA), Unilorin university (Nigeria) and Sultan Qaboos University (Oman). His interest is Artificial Intelligence, Automatic Control Systems, Stochastic Modelling and Simulation, Database, Decision Support Systems, Management Information Systems, and Application of Computer technology in Industry. He has published more than 75 scientific articles in journals and conference proceedings. 